This item was submitted to Loughborough's Research Repository by the author.

Items in Figshare are protected by copyright, with all rights reserved, unless otherwise indicated.

\title{
On the measurement and modelling of high pressure flows in poppet valves under steady-state and transient conditions
}

\section{PLEASE CITE THE PUBLISHED VERSION}

http://dx.doi.org/10.1115/1.4036150

\section{PUBLISHER}

(C) American Society of Mechanical Engineers (ASME)

\section{VERSION}

AM (Accepted Manuscript)

\section{PUBLISHER STATEMENT}

This work is made available according to the conditions of the Creative Commons Attribution-NonCommercialNoDerivatives 4.0 International (CC BY-NC-ND 4.0) licence. Full details of this licence are available at: https://creativecommons.org/licenses/by-nc-nd/4.0/

\section{LICENCE}

CC BY-NC-ND 4.0

\section{REPOSITORY RECORD}

Mohr, Stephan, Henry Clarke, Colin Garner, Neville Rebelo, Andrew Williams, and Huayong Zhao. 2017. "On the Measurement and Modelling of High Pressure Flows in Poppet Valves Under Steady-state and Transient Conditions". Loughborough University. https://hdl.handle.net/2134/24041. 


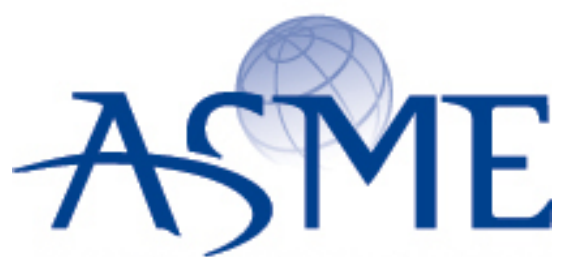

SETTING THE STANDARD

\section{American Society of Mechanical Engineers}

ASME Accepted Manuscript Repository

Institutional Repository Cover Sheet

On the measurement and modelling of high pressure flows in poppet valves $u$ ASME Paper Title: steady-state and transient conditions

\author{
Mohr, Stephan \\ Clarke, Henry \\ Garner, Colin P. \\ Rebelo, Neville \\ Williams, Andrew M.
}

Authors: $\quad$ Zhao, Huayong

ASME Journal Title: J ournal of Fluids Engineering

Volume/Issue _ $139(7), 071104$ Date of Publication (VOR* Online) _Apr 24, 2017

ASME Digital Collection URL: http://fluidsengineering.asmedigitalcollection.asme.org/article.aspx?articleid=2610242 
*VOR (version of record) 
On the measurement and modelling of high pressure flows in poppet valves under steadystate and transient conditions

\section{Stephan Mohr}

Wolfson School of Mechanical, Electrical and Manufacturing Engineering Loughborough University, Leicestershire, UK, LE11 3TU

S.Mohr@lboro.ac.uk

\section{Henry Clarke}

Dearman Technology Centre

Unit 5 Stafford Cross Business Park

Stafford Road, Croydon, Greater London, UK, CRO 4TU

Henry.Clarke@Dearman.co.uk

\section{Colin P. Garner}

Wolfson School of Mechanical, Electrical and Manufacturing Engineering Loughborough University, Leicestershire, UK, LE11 3TU

\section{C.P.Garner@lboro.ac.uk}

\section{Neville Rebelo}

Wolfson School of Mechanical, Electrical and Manufacturing Engineering Loughborough University, Leicestershire, UK, LE11 3TU

N.J.Rebelo@lboro.ac.uk

\section{Andrew M. Williams}

Wolfson School of Mechanical, Electrical and Manufacturing Engineering Loughborough University, Leicestershire, UK, LE11 3TU

A.M.Williams@lboro.ac.uk

\section{Huayong Zhao ${ }^{1}$}

Wolfson School of Mechanical, Electrical and Manufacturing Engineering Loughborough University, Leicestershire, UK, LE11 3TU

H.Zhao2@lboro.ac.uk

\section{ABSTRACT}

Flow coefficients of intake valves and port combinations were determined experimentally for a compressed nitrogen engine under steady-state and dynamic flow conditions for inlet pressures up to 3.2 MPa. Variable valve timing was combined with an indexed parked piston cylinder unit for testing valve flows at different cylinder volumes whilst maintaining realistic in-cylinder transient pressure profiles by simply using a fixed area outlet orifice. A one-

\footnotetext{
${ }^{1}$ Corresponding author
} 
Journal of Fluids Engineering

dimensional modelling approach describing three-dimensional valve flow characteristics has been developed by the use of variable flow coefficients that take into account the propagation of flow jets and their boundaries as a function of downstream/upstream pressure ratios. The results obtained for the dynamic flow cases were compared with steadystate results for the cylinder to inlet port pressure ratios ranges from 0.18 to 0.83 . The deviation of flow coefficients for both cases is discussed using pulsatile flow theory. The key findings include: 1. For a given valve lift, the steady-state flow coefficients fall by up to 21 percent with increasing cylinder/manifold pressure ratios within the measured range given above; 2. Transient flow coefficients deviated from those measured for the steady-state flow as the valve lift increases beyond a critical value of approximately $0.5 \mathrm{~mm}$. The deviation can be due to the insufficient time of the development of steady state boundary layers, which can be quantified by the instantaneous Womersley number defined by using the transient hydraulic diameter. We show that it is possible to predict deviations of the transient valve flow from the steady-state measurements alone.

\section{KEYWORDS}

Poppet valve, transient valve flow coefficient, indexed piston, Womersley number

\section{INTRODUCTION}

Air pollution and climate change, together with the rapid depletion of fossil fuels is driving change across the transport technology sector. Compressed air engines have the potential to provide a significant contribution to the transport sector. Compressed air engines have been studied and used many decades [1, 2], but have recently received a new level of performance and capability by the introduction of Heat Exchange Fluids (HEF) [3]. By way of 
Journal of Fluids Engineering

example, the Dearman Engine is a high efficiency Rankine-cycle expander engine, developed specifically for use with liquid air or liquid nitrogen. It uses the same pressurise-vaporiseexpand-exhaust cycle as other open-cycle Rankine devices, but is differentiated by its incylinder heat transfer process [4], in which HEF is used as a heat reservoir to provide extra heat during the expansion stroke to increase the power output.

Pressure losses through the intake and exhaust systems, particularly valves, contribute significantly to system inefficiency. Therefore, a deeper understanding of high pressure flows through the intake tract and the valves is essential to allow designs of engines with optimal performance and to achieve maximum volumetric efficiency.

Although engine poppet valve flows with their respective pressure drops have been investigated as early as 1906 [5], the first research on intermittent flow coefficients was reported in the 1939 and early 1946 [6, 7]. Stanitz et al [7] concluded that there is a slight increase of the flow coefficient with increasing pressure drop across the inlet valves. Trends in the test data also indicated that the average steady-state and the intermittent flow coefficient were approximately equal for lower engine speeds but the intermittent flow coefficient becomes progressively less than the steady-state equivalent as the engine speed increases. However, although the pressure drops across the inlet valves are relatively small in naturally aspirated Internal Combustion (IC) engines, they can be more than an order of magnitude larger in a compressed air engine and need to be weighted accordingly for the correct determination of the valve flow coefficients.

Fundamental research by Perry [8] on compressible gases through a range of orifices has shown that when the downstream pressure decreases, the mass flow rate did increase. This increase in mass flow continues even after the critical pressure ratio has been passed. This 
Journal of Fluids Engineering

contradicts the expectation of choked mass flow experienced at the critical (sonic) pressure ratio. It was attributed to the change in boundary conditions at the exit planes when the gas separated to form a free jet. Alder et al [9] described how a jet becomes supersonic with its boundaries expanding to adjust to the lower surrounding downstream chamber pressure resulting in a higher flow rate.

A distinction between one-dimensional choking and multi-dimensional choking is therefore very important in determining the flow coefficient for high pressure valve flow. When the one-dimensional mass flow rate is constant for all pressure ratios less than or equal to the critical value, the flow is considered to be one-dimensionally choked. The actual mass flow rate ( ) increases with increasing upstream pressure (i.e. decreasing pressure ratio) beyond the critical value due to the changing shape and location of the multi-dimensional sonic surface around the plane of the orifice lip. In comprehensive theoretical studies by Alder et al. [9] and Jobson [10], a numerical solution of choked and supercritical orifice gas flows tries to explain the increase of flow rate beyond the critical pressure ratio as the downstream jet is becoming supersonic. The pressure ratio needs to be low in order for the position of the sonic surface to stabilize in shape and position, thereby allowing the flow to "choke". Experimental results from for instance Browser et al. [11] underlined the theoretical studies mentioned earlier and showed the onset of choking being approximately $50 \%$ lower than the critical pressure ratio.

In more recent work $[12,13]$ investigating the flow characteristics of fast switching electropneumatic valves for a wide range of downstream/upstream pressure ratios, simplified onedimensional simulations based on Perry's correlation provided a fast and reliable method for the determination of dynamic valve flow coefficients. This modelling approach can assist 
Journal of Fluids Engineering

with early engineering decisions and avoids more costly and time-consuming 3D-CFD (Computational Fluid Dynamics) calculations and experimentation.

In an air engine, the transition towards transient conditions in the intake tract and across the valve gap has to be considered when high inlet pressures and short valve timing are prevalent, with its influence on mass flow rate and hence volumetric efficiency. The investigation presented in this paper describes a test rig enabling novel non-standard dynamic valve flow measurements that allows the characterisation of high pressure poppet valve flow. Through a combination of variable valve timing and a parked but adjustable (i.e. indexed) piston position, both the steady-state and the dynamic valve flow behaviours are determined and quantified in detail. In practice, it is very beneficial to be able to predict the transient valve flow coefficients from the steady state measurements only because transient valve flow tests can be very time-consuming and expensive to cover all different flow conditions. This work has led to a better understanding of the dynamics of high pressure valve flow and can potentially simplify future testing procedures by predicting transient behaviour from steady-state flow data only.

\subsection{VALVE FLOW}

In a compressed air engine with high inlet pressures and short valve opening durations (for achieving maximum expansion ratio), the conditions in the intake tract and around the inlet valves are quite different from those experienced in conventional poppet valve applications, e.g. in conventional IC engines. Initial considerations of the type of inlet port modelling (quasi steady vs. non-steady) and their validation were taken into account by considering the relation of the flow frequency to viscous effects that are expressed in the Womersley number ( ) [14] given by 
Journal of Fluids Engineering

$$
\alpha=r \cdot\left(\frac{n}{v}\right)^{1 / 2}
$$

where $r$ is the radius of the intake tract/port, $n$ the circular frequency and $v$ the kinematic viscosity of the fluid.

The Womersley number can be used to determine whether the steady-state boundary layer has been developed in a dynamic flow; therefore, it can be used to determine whether a flow field is dominated by the quasi-steady, the intermediate, or the inertia effect. The flow with Womersley number $\alpha<1.32$ was reported to be quasi-steady and the flow with $\alpha \geq 28$ was in an inertia dominant region. The so-called intermediate region exists when $1.32<\alpha<28$ [15]. The Womersley number is normally applied to biological systems [16], but has recently been extended to fully turbulent, compressible flows in bent pipes, focussing on engine research [17].

With typical compressed nitrogen engine conditions of high inlet pressures and short valve durations, the flow conditions, according to Equation (1) are mostly inertia dominated and an unsteady modelling approach will be required.

The gas transfer process can also strongly depend on the design of intake sub-systems such as ports, manifolds and dampers and does impact on the efficiency and the performance of the engine.

As a consequence of the high pressure gas flow through the intake tract, the short valve opening can cause expansion waves to propagate back into the inlet manifold and pipe work. These expansion waves can be reflected at open ends of the manifold causing positive pressure waves to be reflected back towards the cylinder. If the timing of these waves can be appropriately arranged through a well-designed intake tract, the positive pressure wave 
Journal of Fluids Engineering

can cause the pressure at the inlet valve during the next valve event to be raised above the average inlet pressure, increasing the volumetric efficiency of the engine.

Real mass flow rates of liquids and gases through orifices can often differ substantially from those predicted from theory for both incompressible and compressible flows. To allow a use of time effective (and therefore low cost) algorithms that can easily and accurately predict the actual mass flow rates $(\dot{m})$, a correction factor called the flow coefficient has historically been incorporated, i.e.

$$
C_{f}=\frac{\dot{m}_{\mathrm{act}}}{\dot{m}_{\text {ideal }}}
$$

where $\dot{m}_{\text {act }}$ is the measured mass flow rates and $\dot{m}_{\text {ideal }}$ the predicted mass flow rates with no frictional loss. There are other ways of defining a flow coefficient, e.g. by introducing the concept of an effective area $A_{\text {eff }}$. The effective area is an area of an imaginary orifice that would produce (in an ideal case) the actual mass flow rate $\dot{m}_{\text {act }}[18]$. The flow coefficient in eq. (2) can then be expressed as

$$
C_{f}=\frac{A_{\text {eff }}}{A_{\text {geom }}}
$$

where $A_{\text {geom }}$ is the geometrical area. The flow coefficient is therefore the ratio of the effective area to the geometrical orifice area. For simplicity, we can assume a flow of a compressible ideal gas through the valve, and then the mass flow rate is given by

$$
\dot{m}=A_{\text {geom }} \cdot C_{f} \cdot C_{m} \cdot \frac{P_{u}}{\sqrt{T_{u}}}
$$


Journal of Fluids Engineering

which is a function of upstream pressure $P_{u}$, upstream temperature $T_{u}$, the flow coefficient $C_{f}$ and the mass flow parameter $C_{m}$, such that the mass flow parameter in the subsonic case is a function of $P_{d} / P_{u}$, but is constant when flow becomes sonic, i.e.

$$
\begin{array}{ll}
C_{m}=\sqrt{\frac{2 \cdot \gamma}{\gamma \cdot(\gamma-1)} \cdot \sqrt{\left(\frac{P_{d}}{P_{u}}\right)^{2 / \gamma}-\left(\frac{P_{d}}{P_{u}}\right)^{(\gamma+1) / \gamma}}} & \text { if }\left(\frac{P_{d}}{P_{u}}\right)>P_{c r} \text { (subsonic) } \\
C_{m}=\sqrt{\frac{\gamma}{R} \cdot\left(\frac{2}{\gamma+1}\right)^{(\gamma+1) /(\gamma-1)}}=\sqrt{\frac{2 \cdot \gamma}{\gamma \cdot(\gamma+1)}}\left(\frac{2}{\gamma+1}\right)^{1 /(\gamma-1)} & \text { if }\left(\frac{P_{d}}{P_{u}}\right) \leq P_{c r} \text { (sonic) }
\end{array}
$$

where

$C_{m}:$ Mass flow parameter $\left[\left(\mathrm{kg} \mathrm{K} \mathrm{J}^{-1}\right)^{1 / 2}\right]$

$P_{u}:$ Upstream pressure in manifold $[\mathrm{Pa}]$

$P_{d}$ : Downstream pressure in cylinder $[\mathrm{Pa}]$

$\gamma$ : Ratio of specific heats [-]

$R$ : Gas constant $\left[\mathrm{Jg}^{-1} \mathrm{~K}^{-1}\right]$

$P_{c r}:$ critical pressure ratio

The flow coefficients for steady flow are generally found experimentally with adequate accuracy, but since flow aspects can change with the pressure ratio as discussed earlier, a slightly more complicated hypothesis is to assume that the flow coefficient $C_{f}$ is a function of the cylinder/manifold pressure ratio which is labelled as the downstream/upstream pressure ratio $P_{d} / P_{u}$. The so called Perry flow coefficient is generally used for sharped edged orifices [8] and can be approximated by a polynomial function of the pressure ratios $P_{d} / P_{u}$ such that

$C_{f}=\left(\left(\left(\left(-1.6827 \cdot \frac{P_{d}}{P_{u}}+4.6\right) \cdot \frac{P_{d}}{P_{u}}-3.9\right) \cdot \frac{P_{d}}{P_{u}}+0.8415\right) \cdot \frac{P_{d}}{P_{u}}-0.1\right) \cdot \frac{P_{d}}{P_{u}}+0.8414$

The critical pressure ratio for which the flow switches from subsonic to sonic can be calculated for nitrogen using 
Journal of Fluids Engineering

$$
\left(\frac{P_{d}}{P_{u}}\right)_{c r}=P_{c r}=\left(\frac{2}{\gamma+1}\right)^{\gamma / \gamma-1}=0.528, \text { if } \gamma=1.4
$$

All models described in the rest of this paper were developed using the platform AMESIM (Advanced Modelling Environment for performing Simulations of engineering systems) distributed by Siemens PLM Software. AMESIM is capable of the modelling and the analysis of multi-domain systems and is based on a 1-D lumped parameter time domain simulation platform. In addition to a dedicated engine library within AMESIM, the thermo-physical properties of $\mathrm{N}_{2}$ were calculated according to NIST (National Institute of Standards and Technology) recommendations [19]. The flow through the test rig's inlet ports, valves, cylinder and outlet ports were modelled with the inclusion of the in-built pneumatic library using the real gas model and taking the effects of dynamics, friction and the forced convective heat transfer into account.

Figure 1 shows a schematic of the model setup used for the valve flow investigations. In this model, an indexed piston configuration is shown, but a cranked piston-expander can be substituted for comparing the in-cylinder pressure traces. With such a model, the effect of changes in the intake tract on torque and specific work output can be determined.

\section{METHODOLOGY}

\subsection{EXPERIMENTAL SETUP}

The experimental investigation focused on a purpose-built test rig that has been designed with a cylinder head and a valve actuation mechanism identical to the Dearman engine, which is a novel liquid nitrogen piston engine with high inlet manifold gas pressure (up to 10 MPa). The cylinder head comprised of two pairs of inlet and outlet valves and was mounted on top of an aluminium cylinder block and liner. A standard Yamaha Rhino piston is kept in a 
Journal of Fluids Engineering

stationary (albeit adjustable) position with the help of a lockable crank mechanism in order to allow measurements of time and volume dependent cylinder pressure build-up. Components of the rig are shown in Fig. 2 and described in Table 1.

During the experiment, it was necessary to capture the thermo-physical parameters of nitrogen along its path starting from the compressed gas cylinder all the way out of the test rig. In the case of the presented rig, these parameters are the nitrogen mass flow rate, its temperatures and pressures. To monitor the dynamic behaviour of the valve flows, fast piezo-resistive pressure sensors with a natural frequency in excess of $100 \mathrm{kHz}$ were used. They were calibrated for a temperature range of $-20^{\circ} \mathrm{C}$ to $125^{\circ} \mathrm{C}$ (Kistler type $4007 \mathrm{C}$ ) resulting in a deviation pressure (\%FSO) of $\leq 1 \%$.

\section{Table 1: Characterisation of the test rig}

The high pressure gas supply mimicked a particular iteration of the Dearman engine intake and supply pipe work that includes a bespoke flow damper (to minimise the flow pulsations) and a forked inlet manifold. In the tests, high pressure nitrogen was supplied by compressed nitrogen gas cylinders and regulated by a two stage regulator with $4.1 \mathrm{MPa}$ maximum feed pressure.

\subsubsection{VALVE DESIGN AND ACTUATION}

The high pressure nitrogen is admitted via a pair of poppet valves and, like in a conventional IC engine, they open into the cylinder. To counterbalance the high force acting on the valve head, a counter piston was mounted on the upper part of the valve stem to stop the valves being forced open by the supply pressure, and to allow the use of valve springs with manageable spring constants. The inlet valves were actuated from an adapted Fiat MultiAir ${ }^{\circledR}$ unit referred to as UniAir ${ }^{\circledR}$. It is a hydraulic lost-motion, fully-variable, electro-hydraulic 
Journal of Fluids Engineering

valve control system that comprised an actuator activated by a mechanical camshaft with an integrated software controlled fast-acting solenoid valve. The inlet cam shaft was driven by a $2.2 \mathrm{~kW} 6$ pole, 3-phase electric motor equipped with variable speed drive inverter.

For simulating realistic in-cylinder pressure profiles in a parked piston configuration, the cylinder pressure relief was managed differently to a conventional engine that uses a cranked piston-expander. Taking advantage of the short inlet valve opening events shortly after piston Top Dead Centre (TDC) as described above, a novel solution was employed by using a well-defined orifice venting the cylinder. The cross section of the orifice has to be adjusted to allow the cylinder pressure to quickly build up during filling, but to drop down to approximately $0.1-0.2 \mathrm{MPa}$ at around half the cycle (corresponding to a crank position of 180 degree or Bottom Dead Centre (BDC) in an engine). This was mechanically achieved with the help of the outlet valves and a lever connected to the outlet camshaft. Table 1 contains the salient test rig parameters used in the experiments.

\subsection{FLOW CONDITIONS AND DATA ANALYSIS}

The flow conditions in both the steady-state and transient experiments are summarized in table 2.

Table 2 Summary of flow conditions in steady-state and transient experiments

\subsubsection{STEADY-STATE FLOW}

The flow efficiency of the entire inlet tract can be determined by measuring the mass flow rate as a function of the intake valve lifts.

In order to discuss a wider variety of valve sizes, a valve lift $(L)$ to valve seat diameter $(D)$ ratio $(L / D)$ is generally used. IC engines typically have a maximum of $L / D$ of 0.25 with 
Journal of Fluids Engineering

racing engines approaching 0.35 . For $L / D$ of up to 0.15 , the flow is mostly controlled by the valve lift, valve seat area as well as seat angle [20]. Higher lift flows are more dominated by the maximum size of the valve port (valve seat area). Flow separation has also been observed for increasing valve lifts where the flow can separate from the valve head and the inner edge of the valve seat [21].

With experiments presented here with $L / D$ ratio of up to 0.15 , the open valve area can be described as the lateral area of a cone having its side perpendicular to the valve seat, as shown in Fig. 3. The geometrical area is therefore given by [6]

$$
A_{\text {geom }}=2 \cdot \pi \cdot\left(R_{o}+\frac{L}{2} \sin \phi \cdot \cos \phi\right) \cdot L \cdot \cos \phi
$$

where $L$ is the valve lift, $\phi$ is the seat angle and $R_{o}$ is the inside radius of the valve seat.

Initially, a set of measurements were conducted to determine the steady-flow coefficient $C_{f}$ for an open cylinder configuration (i.e. no cylinder pressure increase). In all measurements, the mass flow is considered to be choked and hence the flow coefficient could be determined by

$$
C_{f}=\frac{1}{A_{\text {geom }}} \cdot \frac{\dot{m}_{\mathrm{act}}}{\sqrt{\gamma \cdot \rho_{u} \cdot P_{u} \cdot\left(\frac{2}{\gamma+1}\right)^{\frac{\gamma+1}{\gamma-1}}}}
$$

where $\gamma$ is the ratio of specific heats, $\rho_{u}$ is the upstream density and $P_{u}$ is the upstream pressure.

\subsubsection{DYNAMIC VALVE FLOW}

The dynamic valve flow experiments were carried out using an indexed piston setup, as shown in Fig. 2. When using an indexed piston, the cylinder pressure trace will be quite 
Journal of Fluids Engineering

different from the running engine due to the lack of piston movement. In order to mimic the pressure trace of a running engine, a suitable fixed exhaust valve lift is required. In order to find these required exhaust valve lift, the predicted pressure traces from the AMESIM model based on the parked piston configuration (with different fixed exhaust valve lifts) are compared to the predicted pressure trace from another AMESIM model based on the real engine configuration. The exhaust valve lifts which leads to the best match to the pressure trace of a running engine are used in the experiments.

To investigate the dynamic valve flow under different pressure ratio and valve lift conditions, a number of experiments comprising the variation of cylinder volumes were performed and were conducted with nitrogen inlet pressures of approximately $3 \mathrm{MPa}$ and a camshaft rotational speed of $750 \mathrm{rpm}$. The inlet valve opening duration is detailed in table 1.

In the transient flow conditions, the instantaneous flow rate is too fast to be measured accurately using the available instruments. Therefore, a combined experiment and modelling approach was used. The model use the real gas properties from the by the NIST (National Institute of Standards and Technology) REFPROP (Reference Fluid Thermodynamic and Transport Properties Database), the measured valve geometric areas and the transient flow coefficients $\left(C_{f-T}\right)$ defined in Eq. (11) to calculate the cylinder pressure and the total mass flow rate for the whole valve event.

$C_{f-T}=S \cdot C_{f}$

where $C_{f}$ is calculated by using Perry Polynomial defined in Eq. (7) and $S$ is the customdefined scaling factor which depends on the valve lift. 
Journal of Fluids Engineering

The predicted pressure traces and the total mass flow rates using different scaling factors were then compared with the measured instantaneous downstream pressure and the total mass flow rate. The scaling factors which lead to the best match of both the pressure trace and the total mass flow rate were then used to calculate the instantaneous flow coefficients by Eq. (11). Therefore, this approach is effectively taking the measured cylinder pressure traces, the geometric areas, and the total mass flow rates as the boundary conditions to analytically calculate the transient valve flow coefficients. These instantaneous flow coefficients will be referred as 'measured transient flow coefficients' in this paper. Figure 4 shows the comparison between the predicted pressure traces based on these transient flow coefficients and the measured pressure trace for all transient flow conditions.

\subsection{Measurement uncertainty}

The measurement uncertainties for the steady state conditions are mainly attributed to the accuracy of the mass flow meter, the valve lift sensor, and the pressure transducer used to measure the upstream pressure. Through calibrations, the uncertainty of the mass flow meter was found about $\pm 6 \%$; the uncertainty for the valve lift sensor was about $\pm 4 \%$; the uncertainty for the pressure transducer is $\pm 1 \%$. The other fluid properties, including the gas constant and the density, are calculated directly by the NIST REFPROP using the measured instantaneous pressure and temperature. The temperature was measured using a K-type thermocouple with calibrated uncertainty of $\pm 1 \%$ so the uncertainties for the fluid properties were below $\pm 1.5 \%$. Flow conditions and temperatures were stable after approximately one minute of running the rig and the data will be collected afterwards. Therefore, the uncertainty analysis indicates the measured uncertainties for the steadystate flow coefficients were below $\pm 7 \%$. 
Journal of Fluids Engineering

With the uncertainties of the valve lift sensor, mass flow meter and the pressure transducer similar to the steady state cases, the uncertainty analysis indicates the measured uncertainties for the transient flow coefficients were below $\pm 5 \%$. The ratios between the transient flow coefficients and the steady-state flow coefficients are used to quantify the difference between transient flow and steady-state flow conditions. The uncertainty for the flow coefficients ratios were below $\pm 9 \%$.

\section{RESULTS AND DISCUSSION}

\subsection{STEADY-STATE VALVE FLOW RESULTS}

Figure 5 shows results for steady-state valve flow as a function of valve lift. Using Equation (10), the flow coefficients were calculated by using the measured inlet pressure, mass flow rate and the fluid properties (i.e. and u) from the NIST database [19].

Figure 6 shows the flow coefficients for a fixed valve opening as a function of manifold/cylinder pressure ratio and reveals a declining coefficient towards increasing pressure ratios. It was possible to fit the data points with the use of a modified Perry polynomial [8] with a scaling factor of 0.456 applied to Eq. (7), which was previously derived for sharped edged orifices.

The results show that the modified Perry polynomial is able to provide the trend of the declining flow coefficient that is caused by the change in boundary conditions at the poppet valve's exit and the formation of a free jet. With the jet boundaries expanding due to a lower cylinder pressure (i.e. decreasing manifold/cylinder pressure ratio), the mass flow rate is finally only be limited by the sonic flow condition in the throat.

\subsection{DYNAMIC VALVE FLOW RESULTS}


Journal of Fluids Engineering

The main purpose of the dynamic valve flow tests is to check whether it is feasible to predict the dynamic valve flow coefficients in different conditions from the measured steady-state valve flow coefficients only. The detailed comparisons are summarized below which followed by a more in-depth discussion about the fundamental difference between the transient valve flow and steady-state valve flow conditions.

To allow a comparison with the steady-state flow coefficients, the measured transient flow coefficients have been plotted as a function of cylinder to manifold pressure ratio as in Fig. 7 . Figure 7 (right) shows the flow coefficients in transient conditions could be fitted well with a scaled Perry polynomial for each valve lift. The fitted Perry's polynomial can then be used to interpolate the measured transient flow coefficients to different valve lift and pressure ratio, including the choked flow coefficients (which are very close to the measured flow coefficients at low cylinder/manifold pressure ratio). The comparison between these interpolated transient choked flow coefficients and the measured steady-state choked flow coefficients are shown in Fig. 7 (left). The difference of the transient to steady state flow coefficients is also shown in Fig. 7 (left). It clearly shows the close agreement between the transient and steady state flow coefficients occurs only at small valve lifts. A more detailed comparison between the transient and steady state flow coefficients at $0.5 \mathrm{~mm}$ valve lift is plotted in Fig. 6 (bottom). It shows the transient flow coefficients are consistently smaller than the steady state condition.

To explain these differences we now revisit the Womersley number $\alpha$ given in Eq. (1) as it is effectively defined as the ratio of the pulsating inertial forces and the viscous forces. During the transient valve flow, the characteristic length $(r)$ in the Womersley number can be defined as the hydraulic diameter for the intake flow. A smaller valve lift means smaller 
Journal of Fluids Engineering

hydraulic diameter so will lead to a smaller Womersley number, which means the pulsating inertial force is relatively small compared to the viscous forces. As a result, the viscous force tends to smooth out any flow disturbance so the transient flow will behave in a more similar manner to the steady state flow. With increasing valve lift, a larger Womersley number reflects increasing pulsating inertial forces which will lead to more dynamic flow conditions.

In pulsating flows in pipes, the interaction between viscous and inertial effects produces a velocity profile with significant deviation from the parabolic shape of a steady-state flow. Loudon and Tordessillas [16] discuss how with a larger Womersley number the boundary layer thickness continues to decrease as the maximum of the velocity moves away from the centre towards the walls, contributing to higher friction losses. However, within the short valve-valve seat gap, the boundary layers will not have enough time to be formed; hence an insufficient entrance length would hinder a fully hydrodynamically developed velocity profile. In Fig. 8 , the ratio of the steady state to the transient flow coefficient is plotted against the Womersley number $(\alpha)$ shows that the pressure ratio starts to deviate from unity at a critical $\alpha \approx 30$. As $\alpha$ increases, the ratio gradually increases and then converges towards a stable value at $\approx 1.3$. This can be explained by the effect of $\alpha$ on the boundary layer formation. As $\alpha$ increases, the boundary layer thickness is reduced which comes together with an increase in the velocity gradient within the boundary layer to satisfy the mass continuity. A larger velocity gradient will lead to a larger frictional loss and, therefore, yielding a lower flow coefficient compared to the steady-state value (i.e. larger pressure ratio). As $\alpha$ further increases, the boundary layer thickness will keep reducing until a point where its thickness is close to the value of relative surface roughness of the material. Further increase in $\alpha$ will not be able to further reduce the boundary layer thickness and 
Journal of Fluids Engineering

therefore the frictional loss so that the ratio between the transient flow coefficient and the steady- state one converges to a single value. This region could be named as the 'fully rough region' adopted from the similar concept in internal turbulent flow where the frictional coefficient is only a function of relative roughness.

To further investigate the validity of the scaled Perry's polynomial on transient valve flow behaviour, these fitted scaled Perry's polynomials are used in AMESIM to predict the transient upstream pressure traces, the downstream cylinder pressure traces, and the average mass flow rate in different cylinder volume setup. Figure 9 shows the maximum incylinder pressure built-up for three different nitrogen manifold pressures for a test run of $525 \mathrm{rpm}$ rotational cam shaft speed and a 30 degree inlet valve opening. The modelled average mass flow rate has also been compared and shows good agreement with the experiment. Comparison between the measured pressure traces and modelling results are shown in Fig. 10. It clearly shows the modelling results replicating the pressure fluctuation in the manifold and also the lower pressure build-up in the larger cylinder volume.

\section{CONCLUSIONS}

The development of a dynamic valve flow test rig provides a valuable tool for the direct comparison of the steady-state and transient high pressure poppet valve flow characteristics. Through a combination of variable valve timing and an adjustable piston position configuration, the dynamic valve flow behaviour which mimics the valve flow in running engines has been analysed in some detail.

The high pressure poppet valve flow has been measured for steady-state and transient flow conditions. A one-dimensional modelling approach, taking into account the variation of the 
Journal of Fluids Engineering

cylinder/manifold pressure ratio, has been developed to predict the transient flow coefficients with good accuracy (within 7\% agreement with experimental data).

Experimental and model results for steady-state and transient valve flows suggest a manifold/cylinder pressure ratio dependent flow coefficient with the transient valve flow additionally affected by the pulsating frequency and the valve lift. For example, the flow coefficients have reduced by as much as 21 percent over the range of measured cylinder/manifold pressure ratios when the valve lift is $0.5 \mathrm{~mm}$.

Differences in the measurements of steady-state and transient valve flow have been attributed to the relative strength of the pulsating inertial force and the fluids viscous force. The relative strength can be represented by using the Womersley number which based on the hydraulic valve diameter and the frequency of the valve events. The experiments suggest a critical Womersley number of $\alpha \approx 30$. The transient flow coefficients are similar to the steady-state ones when the Womersley number is below the critical value but they can be quite different when the Womersley number is larger than the critical value.

From only measuring the steady-state valve flow and using scaling factors, predictions for dynamic valve flow can be undertaken. For further establishing the steady-state and transient flow correlations, further studies will investigate the effects of rig speed, valve timing and lifts on the dynamics flow coefficients.

The significant outcome of the presented research shows that we are able to predict deviations of the transient valve flow from the steady-state measurements alone for manifold pressures of up to $3.2 \mathrm{MPa}$. 
Journal of Fluids Engineering

\section{ACKNOWLEDGMENT}

The authors would like to acknowledge all the partners working in the Innovate UK 'COOL-E' project: Dearman Engines, Horiba-MIRA and Air Products for their support and insightful discussions during the project.

\section{FUNDING}

This project was partially funded by Innovate UK (Project no.: 101561). 
Journal of Fluids Engineering

\section{NOMENCLATURE}

\begin{tabular}{|c|c|}
\hline$A_{\text {eff }}$ & Effective area \\
\hline$A_{\text {geom }}$ & Geometrical area \\
\hline$C_{f}$ & Flow coefficient \\
\hline$c_{m}$ & Mass flow parameter \\
\hline$D$ & Valve diameter \\
\hline$L$ & Valve lift \\
\hline$\dot{m}$ & Mass flow rate \\
\hline$\dot{m}_{\text {act }}$ & Actual/measured mass flow rate \\
\hline$\dot{m}_{\text {ideal }}$ & Theoretical flow rate with no frictional loss \\
\hline$n$ & Circular frequency \\
\hline$P_{c r}$ & Critical pressure ratio \\
\hline$P_{d}$ & Downstream pressure \\
\hline$P_{u}$ & Upstream pressure \\
\hline$r$ & Radius of the intake tract/port \\
\hline$R$ & Gas constant \\
\hline$R_{0}$ & Inside radius of the valve seat \\
\hline$T_{u}$ & Upstream temperature \\
\hline$\alpha$ & Womersley number \\
\hline$v$ & Kinematic viscosity \\
\hline
\end{tabular}




$\begin{array}{ll}\rho_{\mathrm{u}} & \text { Upstream gas density } \\ \phi & \text { Seat angle } \\ \gamma & \text { Ratio of specific heats } \\ \text { AMESIM } & \text { Advanced Modelling Environment for performing Simulations of } \\ & \text { engineering systems } \\ \text { BDC } & \text { Bottom dead centre } \\ \text { IC } & \text { Internal Combustion } \\ \text { HEF } & \text { Heat exchange fluid } \\ \text { Re } & \text { Reynolds number and similar abbreviations do not use italics } \\ \text { CFD } & \text { Computational Fluid Dynamics } \\ \text { TDm } & \text { Revolutions per minute } \\ & \text { Top dead centre }\end{array}$

\section{REFERENCES}

[1] Papson, A., Creutzig, F., and Schipper, L., 2010, "Compressed air vehicles: Drive-cycle analysis of vehicle performance, environmental impact, and economic costs,"

Transportation Research Record: Journal of the Transportation Research Board, No. 2191, Transportation Research Board of the National Academies, Washington,D.C., 2010, pp 67-74

[2] Huang, C.Y., Hu, C.K., Yu, C.J., and Sung, C.K., 2013, "Experimental investigation of the performance of a compressed-air driven piston engine," Energies, 6(3), pp. 1731-1745

[3] Dearman, P.T., 2002, "Engines driven by liquefied or compressed gas," Patent No. EP 1257733 A1

[4] Owen, N., Clarke, H., Charters, H., Trembley, J., Garner, C.P., Mohr, S., Williams, A.W., and Zhao, H, 2015, "Development of a High-Efficiency Liquid-Air Engine For Cooling, Heat Recovery and Power," IVTMS 12, East Midlands Conference Centre, Nottingham.

[5] Lucke, C.E., 1906, “The pressure drop through poppet valve," ASME Trans, 27(1099), pp. 232-301 
[6] Waldron, C.D., 1939, "Intermittent-Flow coefficient of the poppet valve," NACA TN No. 701.

[7] Stanitz, J.D., Lucia, R.E., and Masselle, F.L., 1946, "Steady and intermittent flow coefficients of poppet intake valves," National advisory committee for Aeronauts, Technical note No.1035.

[8] Perry, J.A., 1949, “Critical flow through sharp-edged orifices," Trans. ASME, 71.

[9] Alder, G.M., 1979, "Numerical Solution of choked ideal gas flow through orifices and convergent nozzles," Journal Mech. Eng. Sci., 21(3), pp. 197-203

[10] Jobson, D.A., 1955, "On the flow of a compressible fluid through orifices," Proc. Inst. Mech. Eng., London, 16, pp. 767-772

[11] Browser, W.B. Jr, Eisler, E., Filkorn, E.J., Gonenc, J., Plati, C., and Stagnetti, J., 1993, “On the compressible flow through an orifice," Transactions of the ASME, 115, pp. 660-664

[12] Szente, V., and Vad, J., 2003, "A semi-empirical model for characterisation of flow coefficient for pneumatic solenoid valves," Periodica Polytechnica Ser. Mech. Eng., 47(2), pp. 131-142

[13] Szente, V., and Vad, J., 2003, "Computational and experimental investigation on the flow characterises of small pneumatic solenoid valves," HEFAT2003, 2nd International Conference on Heat Transfer, Fluid Mechanics and Thermodynamics, Zambia

[14] Womersley, J.R., 1955, "Method for the calculation of flow and viscous drag in arteries when the pressure gradient is known," J. Physiol., 127, pp. 553-563

[15] Carpinlioglu, M.O., 2015, “An overview on pulsatile flow dynamics," J. Thermal Eng., 1(6), pp. 496-504

[16] Loudon, C, and Tordessillas, A., 1998, "The use of the dimensionless Womersley number to characterize the unsteady nature of internal flow," J. theor. Biol., 191, pp. 63-78

[17] Kalpakli, A., Orlu, R., Tillmark, N., and Alfredsson, P.H., 2011, "Pulsative turbulent flow through pipe bends at high Dean and Wormersly numbers," 13th European Turbulence Conference (ETC13), Journal of Physics: Conference series 318, 092023.

[18] Lumley, J.L., 1999, “Engines: an introduction," Cambridge University press. Cambridge, UK, ISBN 978-0521644891.

[19] NIST Standard Reference Database, 2010, http://www.nist.gov/srd/fluids.cfm.

[20] Ismail, A.R., and Bakar AR, 2008, " An Investigation of valve lift on air flow and coefficient of discharge of four stroke engines based on experiment," American Journal of Applied Science, 5(8), pp. 963-971

[21] Heywood, J.B., 1988, "Internal combustion engine fundamentals," McGraw-Hill, New York, ISBN 0-007-100499-8 


\section{Figure Caption List}

Fig. 1 Schematic of the pneumatic valve flow models for a piston-expander and an indexed piston

Fig. 2 Schematic of the dynamic valve flow rig used

Fig. 3 Sketch for the calculation of the geometrical valve area at different lift $(L)$

Fig. 4 Comparison between the modelled pressure traces used to calculate the transient flow coefficients and the measured pressure traces for all transient flow conditions

Fig. 5 Steady-state nitrogen valve flow results with an open cylinder configuration

Fig. 6 Valve flow as a function of cylinder/manifold pressure ratio. Top: The effective and geometrical inlet valve area at a valve lift of $0.5 \mathrm{~mm}$. Bottom: The flow coefficient as a function of pressure ratio for an inlet valve lift of $0.5 \mathrm{~mm}$ for steady state and transient flow. The solid black line is Perry's polynomial with a scaling factor of 0.456 . The vertical dashed line represents the critical pressure ratio.

Fig. 7 Left: Steady-state nitrogen valve flow coefficients (for choked conditions) compared with the transient flow coefficients (at pressure ratio zero) derived from fitting modified Perry polynomials to the experimental results for three cylinder volumes (declining flow coefficient with increasing pressure ratio) at comparable valve lifts (VL) (right). The vertical dashed line represents the critical pressure ratio.

Fig. 8 Ratio of the measured steady state and transient flow coefficients as a function of Womersley number

Fig. 9 Comparison of modelled and measured maximal cylinder pressure and average mass flow rate for three different nitrogen inlet pressures. The exhaust valve lift is held constant for all three test points.

Fig. 10 Comparison of the measured (bottom) and modelled (centre) pressures in the manifold (solid line) and the cylinder (broken line) for two different cylinder volumes. The inlet valve lift is shown on top

\section{Table Caption List}

Table 1 Characterization of the test rig

Table 2 Summary of flow conditions in steady-state and transient experiments 
Journal of Fluids Engineering

\section{Tables}

Table 1: Characterisation of the test rig

\begin{tabular}{ll}
\hline Bore & $102 \mathrm{~mm}$ \\
Stroke & Max. 84 mm \\
Cylinder dead volume & $30 \mathrm{~cm}^{3}$ \\
Cylinder swept volume & $686 \mathrm{~cm}^{3}$ \\
Inlet valve diameter & $21 \mathrm{~mm}$ \\
Inlet valve seat angle & $30^{\circ}$ \\
Exhaust valve diameter & $40 \mathrm{~mm}$ \\
Inlet valve start open & $15^{0} \mathrm{after}$ TDC \\
Inlet valve open & $20-30^{\circ}$ \\
Camshaft speed & $0-750 \mathrm{rpm}$ \\
Nitrogen Inlet pressures & 3 to $35 \mathrm{bar}$ \\
\hline
\end{tabular}


Journal of Fluids Engineering

Table 2 Summary of flow conditions in steady-state and transient experiments

\begin{tabular}{lll}
\hline parameter & Steady-state & Transient \\
\hline Inlet pressures $[\mathrm{MPa}]$ & $0.3-3$ & $1.6-3.2$ \\
Mass flow rates $[\mathrm{kg} / \mathrm{s}$ ] & $0-0.09$ & $0-0.035$ \\
Pressure Ratios [ - ] & $0.179-0.826$ & $0.180-0.478$ \\
Flow coefficient $\left[C_{f}\right.$ ] & $0.301-0.382$ & $0.310-0.356$ \\
Womersley number [ ] & - & $26.5-80.1$ \\
Rig speed [RPM] & 0 & 750 \\
\hline
\end{tabular}




\section{FIGURES}

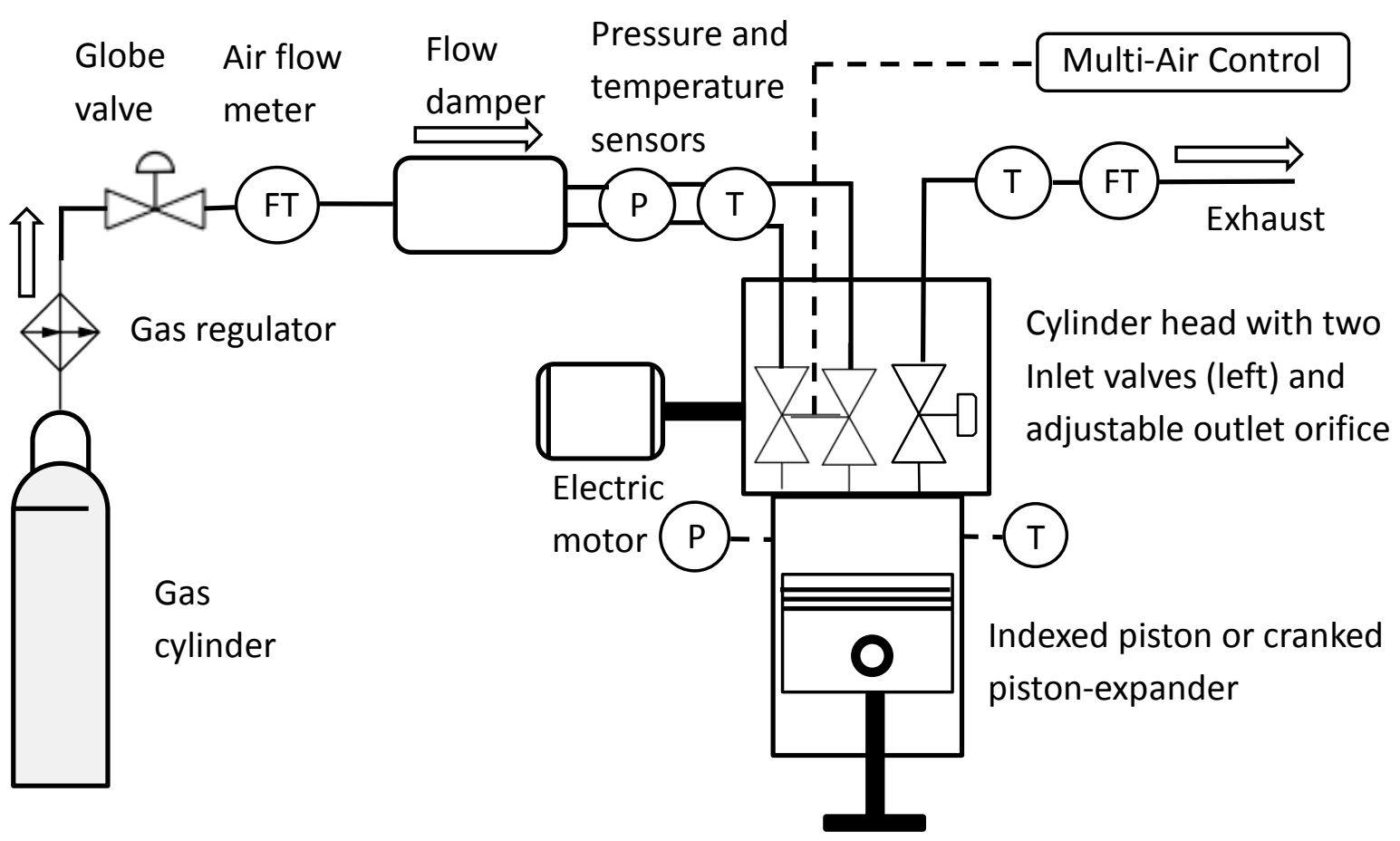

Fig. 1 Schematic of the pneumatic valve flow models for a piston-expander and an indexed piston 


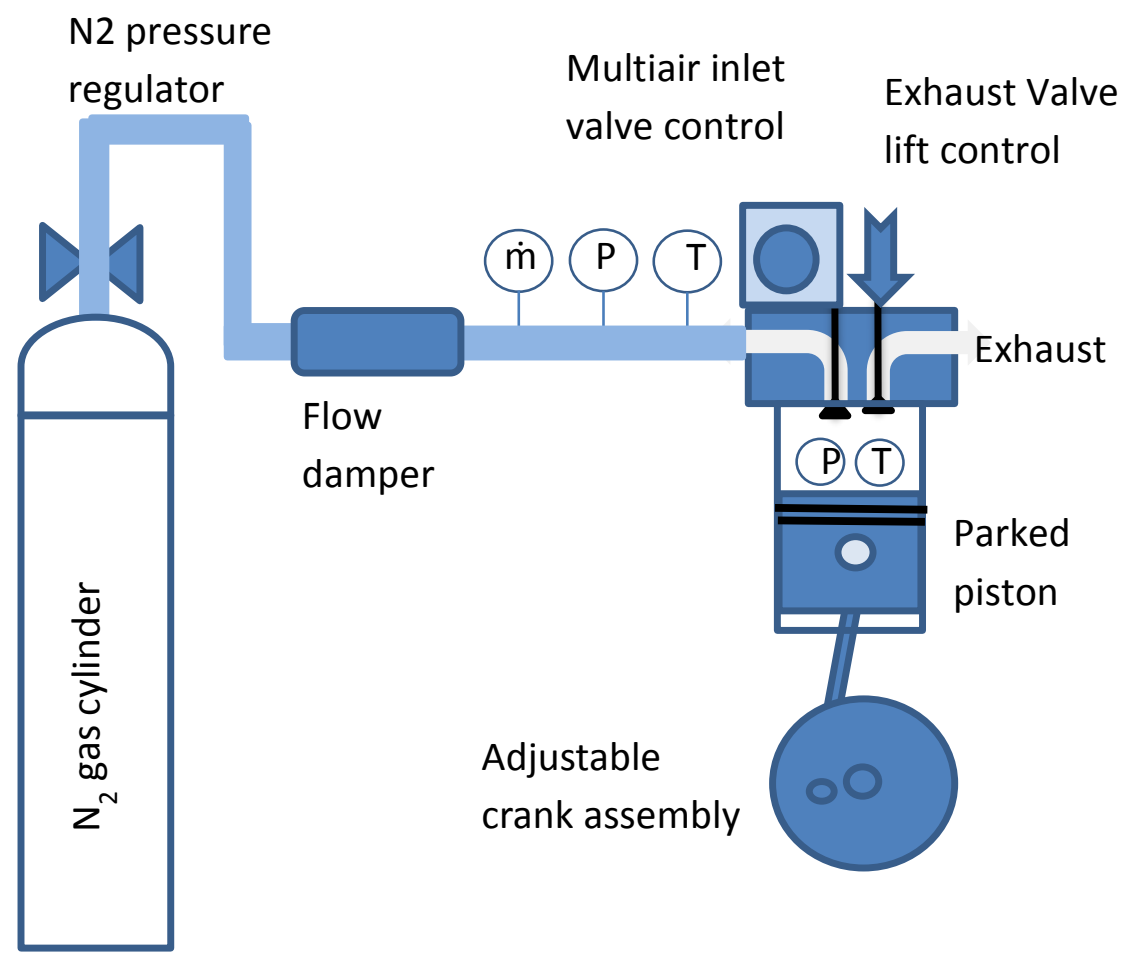

Fig. 2 Schematic of the dynamic valve flow rig used 
Journal of Fluids Engineering

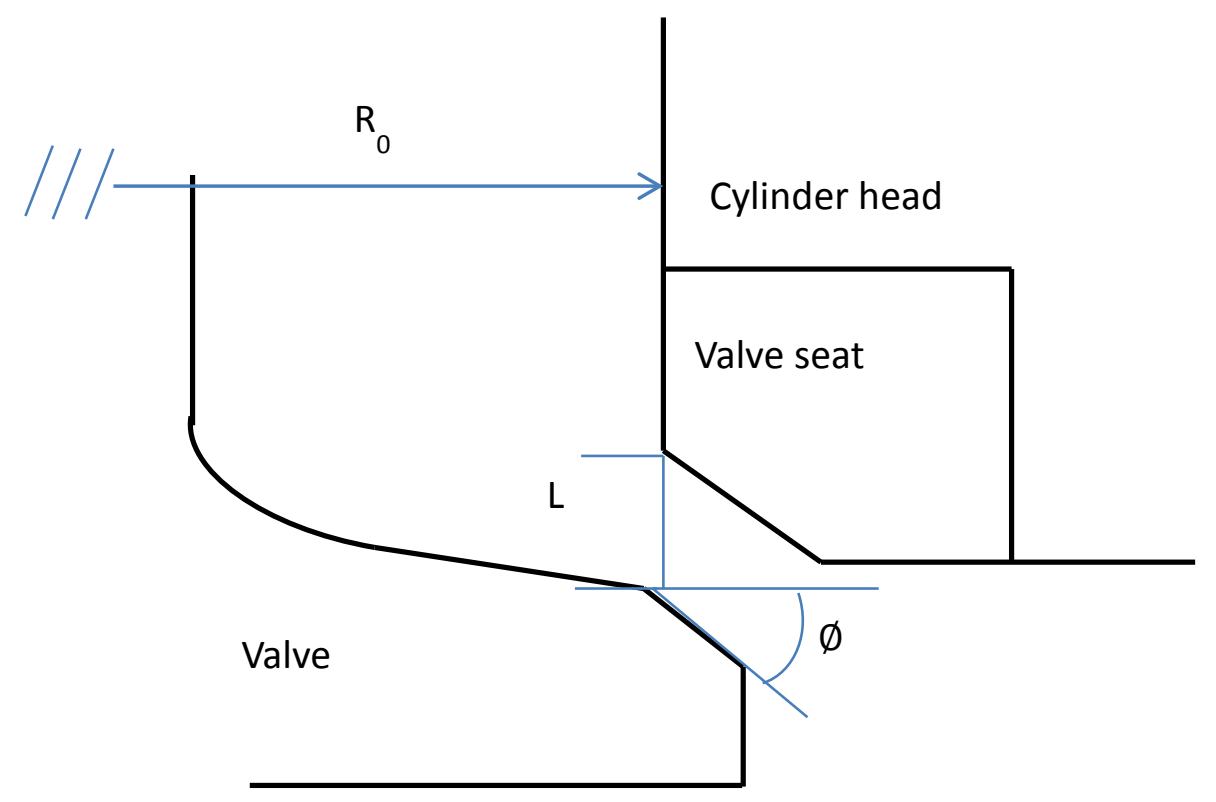

Fig.3 Sketch for the calculation of the geometrical valve area at different lift $(L)$. 


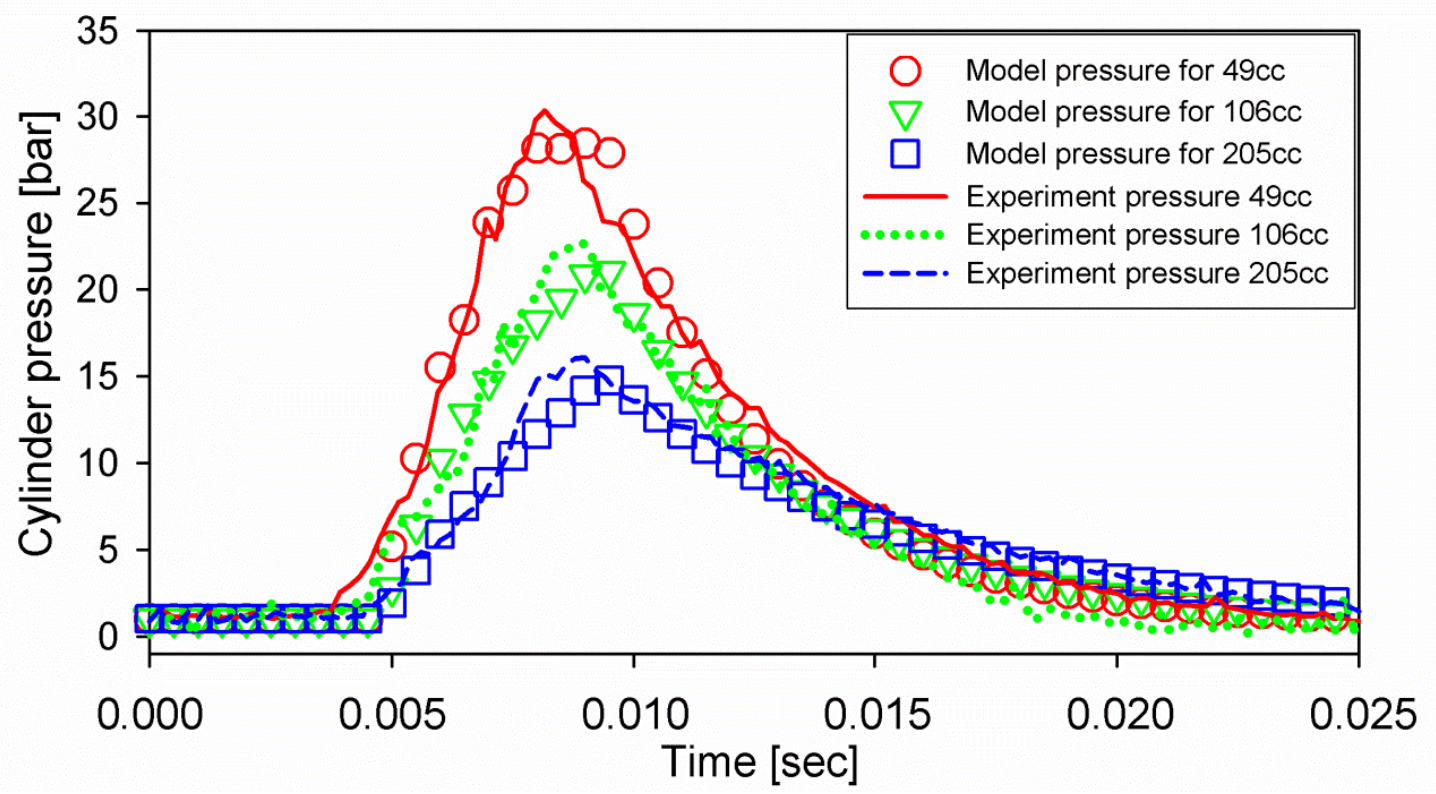

Fig. 4: Comparison between the modelled pressure traces used to calculate the transient flow coefficients and the measured pressure traces for all transient flow conditions 


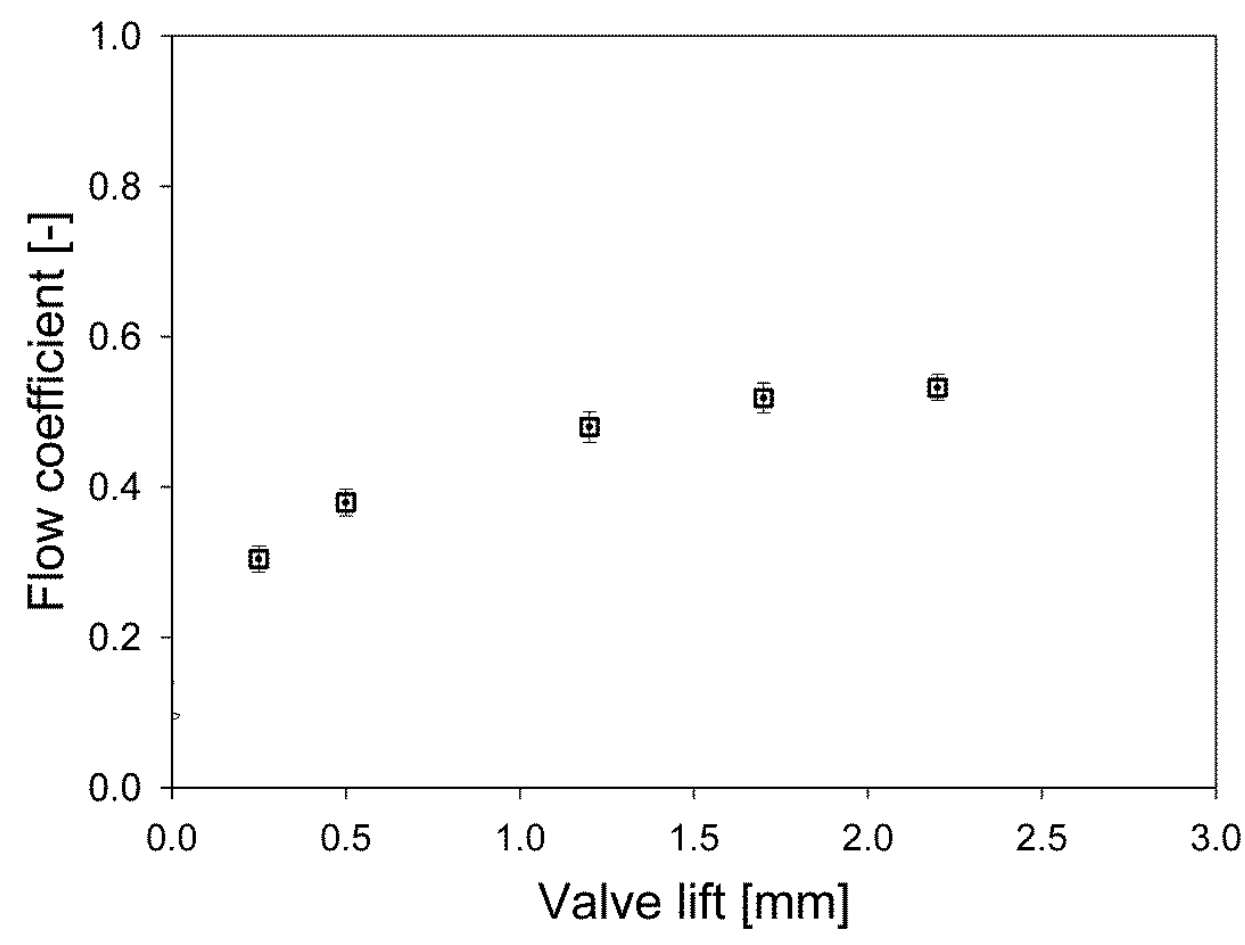

Fig. 5 Steady-state nitrogen valve flow results with an open cylinder configuration 


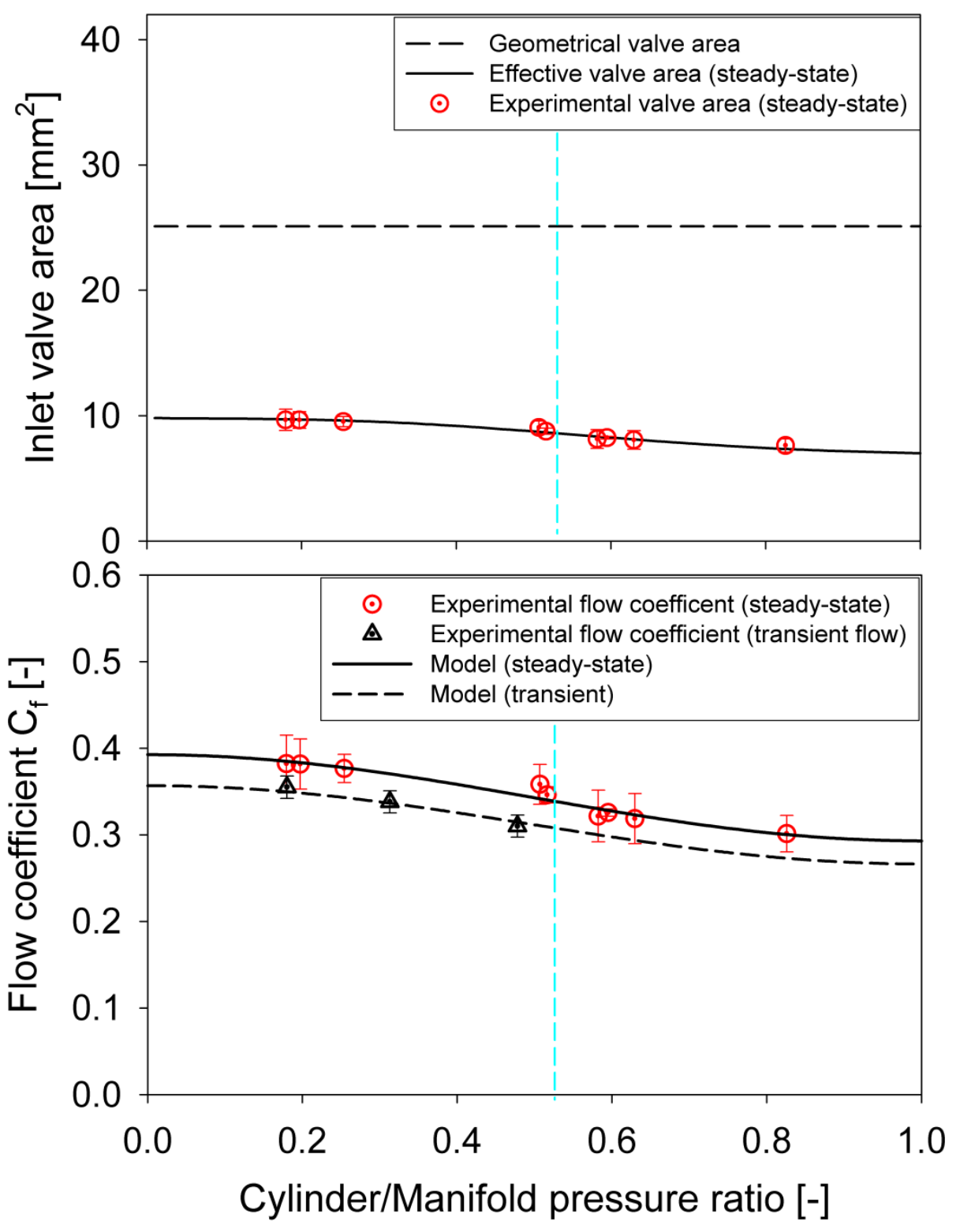

Fig. 6 Valve flow as a function of cylinder/manifold pressure ratio. Top: The effective and geometrical inlet valve area at a valve lift of $0.5 \mathrm{~mm}$. Bottom: The flow coefficient as a function of pressure ratio for an inlet valve lift of $0.5 \mathrm{~mm}$ for steady state and transient flow. The solid black line is Perry's polynomial with a scaling factor of 0.456 . The vertical dashed line represents the critical pressure ratio. 


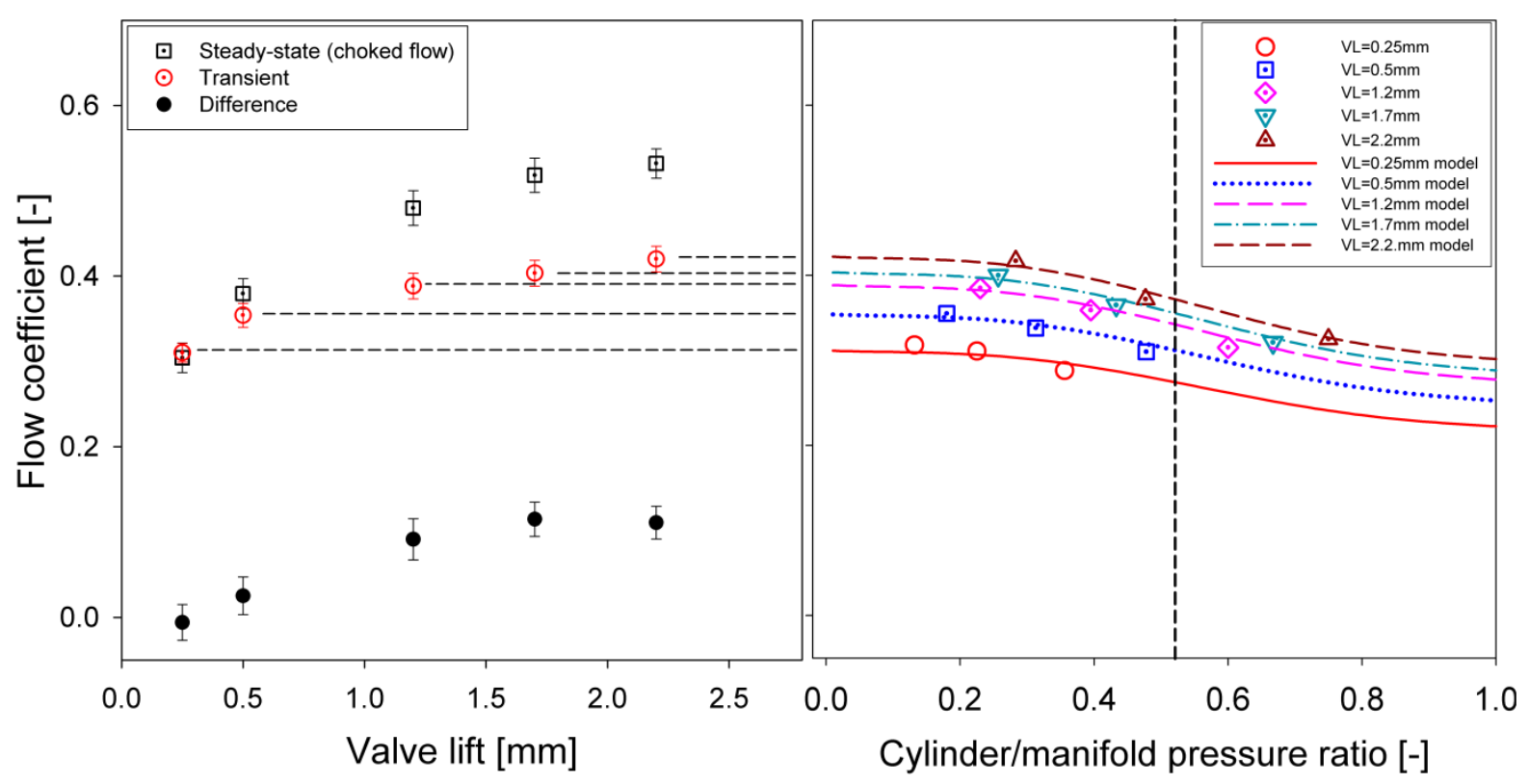

Fig. 7 Left: Steady-state nitrogen valve flow coefficients (for choked conditions) compared with the transient flow coefficients (at pressure ratio zero) derived from fitting modified Perry polynomials to the experimental results for three cylinder volumes (declining flow coefficient with increasing pressure ratio) at comparable valve lifts (VL) (right). The vertical dashed line represents the critical pressure ratio. 


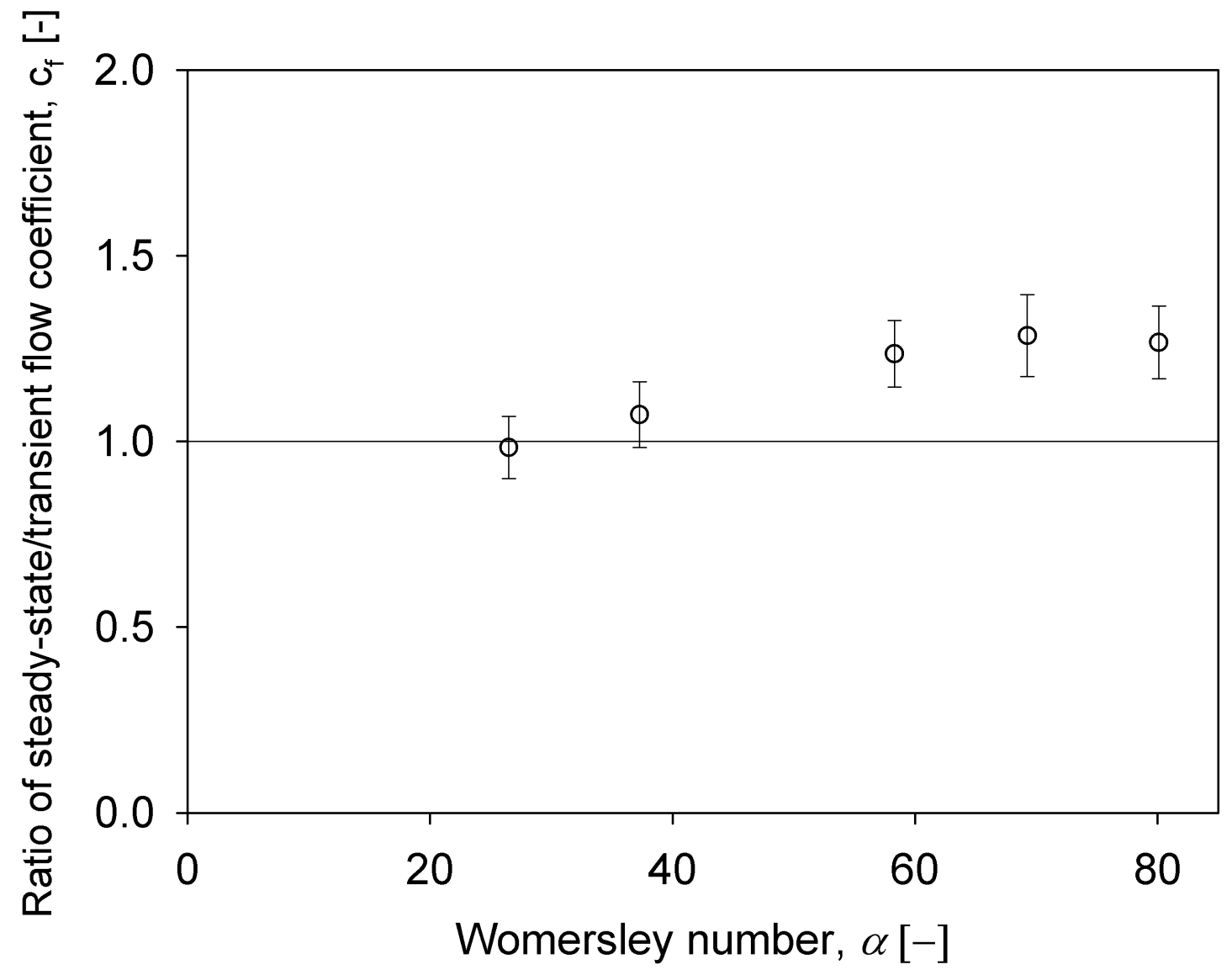

Fig. 8 Ratio of the measured steady state and transient flow coefficients as a function of Womersley number 

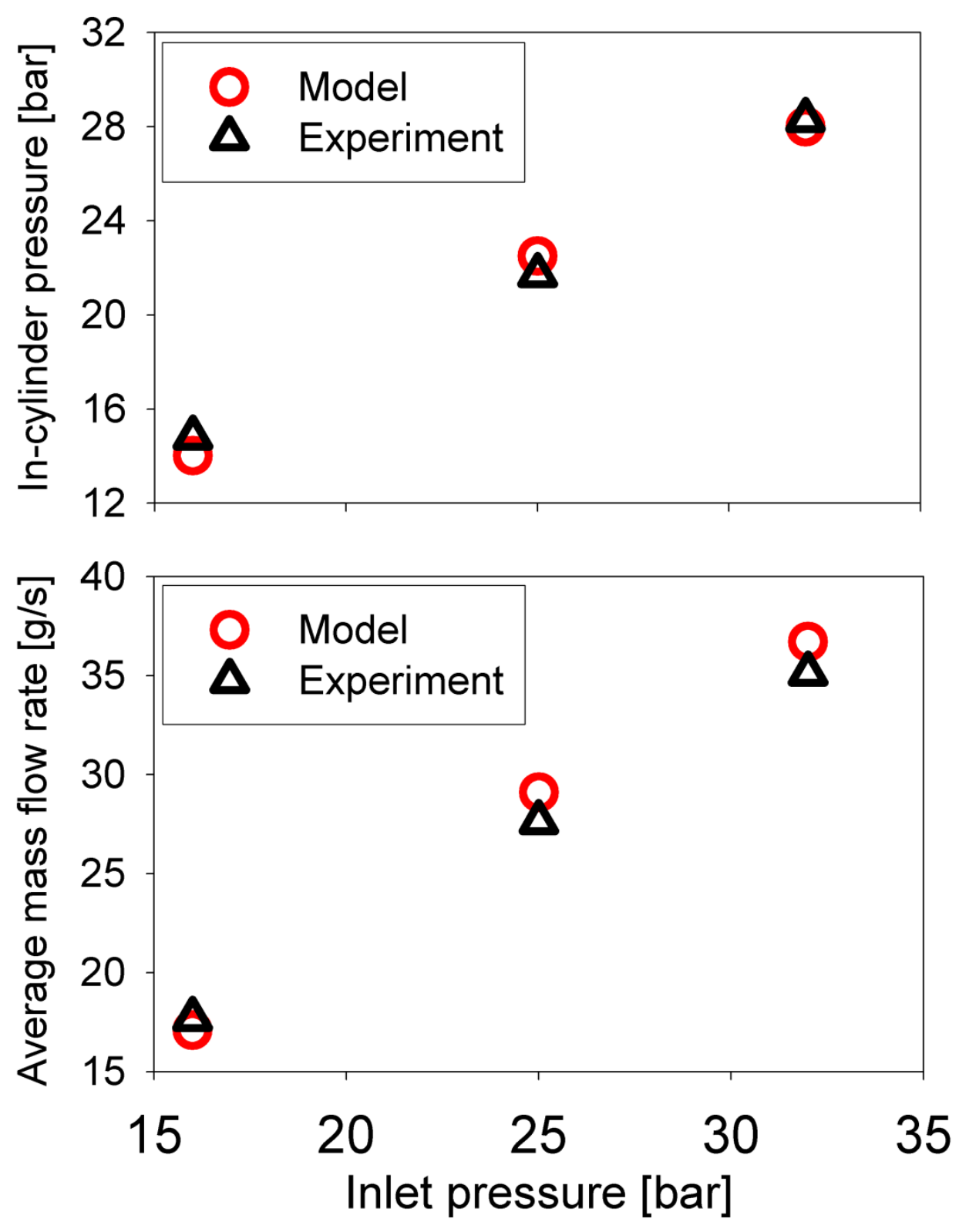

Fig. 9 Comparison of modelled and measured maximal cylinder pressure and average mass flow rate for three different nitrogen inlet pressures. The exhaust valve lift is held constant for all three test points. 

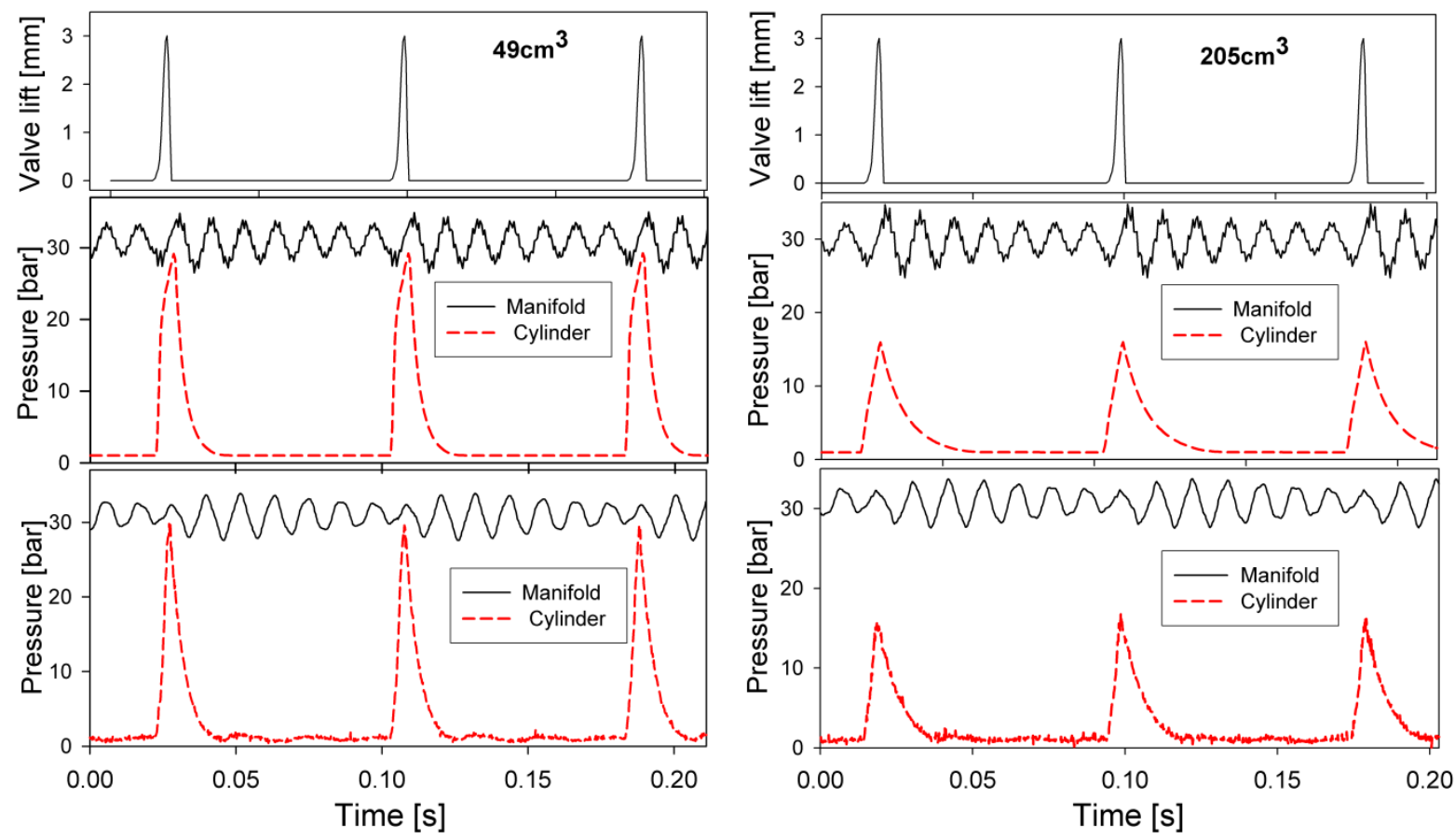

Fig. 10 Comparison of the measured (bottom) and modelled (centre) pressures in the manifold (solid line) and the cylinder (broken line) for two different cylinder volumes. The inlet valve lift is shown on top 